\title{
Elephants in Addo Elephant National Park, South Africa: reconstruction of the population's history
}

\author{
Anna M. Whitehouse and Anthony J. Hall-Martin
}

\begin{abstract}
The history of the Addo elephant population in South Africa, from the creation of the Addo Elephant National Park (AENP) in 1931 to the present (every elephant currently living within the park is known), was reconstructed. Photographic records were used as a primary source of historical evidence, in conjunction with all documentation on the population. Elephants can be identified in photographs taken throughout their life by study of the facial wrinkle patterns and blood vessel patterns in their ears. These characteristics are unique for each elephant and do not change during the individual's life. The life histories of individual elephants were traced: dates of birth and death were estimated and, wherever possible, the identity of the individual's mother was ascertained. An annual register
\end{abstract}

\section{Introduction}

The benefits of long-term population research are increasingly being acknowledged (Martin, 1978; Moss, 1981, 1988; Goodall, 1986; Smuts et al., 1987; Wells, 1991). However, as a result of logistical, financial and other constraints, examples of successful detailed longterm studies are inevitably few. Moss's (1988) longterm study in Amboseli, Kenya, initiated in 1972, remains an exception among elephant research projects, the majority of which span just a few years. Owing to the longevity and slow breeding rate of elephants, demographic data obtained from short-term studies may produce misleading results. This was demonstrated in Amboseli, where the reproductive rates and calf survival observed during the early years of the study, which coincided with a drought, were later identified, in the light of longer term data, as being exceptionally low (Moss, 1988). As Martin (1978) pointed out: 'Ideally an elephant study would follow

Anna M. Whitehouse (née Woodd) (corresponding author) Terrestrial Ecology Research Unit, Department of Zoology, University of Port Elizabeth, PO Box 1600, Port Elizabeth 6000, South Africa. (Address for correspondence: Addo Elephant National Park, PO Box 52. Addo 6105, South Africa). E-mail: zlbamw@zoo.upe.ac.za

Anthony J. Hall-Martin South African National Parks, PO Box 787 Pretoria 0001, South Africa.

Received 9 February 1999. Accepted 2 September 1999 of elephants living within the population, from 1931 to the present, was compiled, and maternal family trees constructed. Preliminary demographic analyses for the period 1976-98 are presented. The quantity and quality of photographs taken during these years enabled thorough investigation of the life histories of all elephants. Prior to 1976, insufficient photographs were available to provide reliable data on the exact birth dates and mothers' identities for every calf born. However, data on annual recruitment and mortality are considered sufficiently reliable for use in analyses of the population's growth and recovery.

Keywords Addo Elephant National Park, demography, elephant, individual recognition, population history.

the life history of a generation of elephant from birth to death, but whereas this is quite feasible in certain animal species, it would involve more than the lifetime of a research worker in the case of elephant'.

This paper describes a study of the Addo elephant population in which a detailed reconstruction of the population's history, based on tracing known individuals' life histories, was used to provide long-term demographic data.

The Addo Elephant National Park (AENP), situated c. $60 \mathrm{~km}$ north-north-east of Port Elizabeth in the Eastern Cape Province of South Africa, was proclaimed in 1931 to protect the last surviving elephants in the region. Although the area supported South Africa's largest elephant population at the turn of the century (Hall-Martin, 1992), conflicts with the local farming community led to an attempt to eradicate the Eastern Cape elephants (Hoffman, 1993). Just 11 survivors formed the founder population of the AENP, which currently supports more than 280 elephants. No immigration has occurred during the park's history and, with the exception of four calves translocated out of the population in 1979, there has been no emigration. An elephant-proof fence currently contains the population within an area of $103 \mathrm{sq} \mathrm{km}$.

Two detailed studies of the elephant population have been conducted: one by A.J.H.-M. between 1976 and 1979, and an ongoing study initiated by A.M.W. in 1996. In both studies every elephant within AENP was 
known to the researcher, and photographic identification files of the population were compiled. In addition, some form of record keeping, chiefly by wardens and rangers, has been in operation throughout the history of the park.

The relatively small size of the population, its closed nature, and the existence of some records on the population throughout the park's life-span all facilitated the reconstruction of its history. By tracing the life history of each individual elephant that has lived within the park since its creation, and identifying their dates of birth and death, and the identity of the mother of each calf born, maternal family trees could be compiled. This provides a detailed demographic data set spanning the 67 years of the park's history, and documenting the recovery of the population from near extinction and its growth to the present day.

\section{Methods}

\section{Current population}

Various characteristics can be used to facilitate identification of individual elephants (Douglas-Hamilton, 1972; Moss, 1988, 1996). These include: sex; age and body size; ear shape and any notches and holes present; patterns of blood vessels in the ears and wrinkles on the face; size, shape and configuration of the tusks; lumps on the body; breaks, kinks or baldness of the tail; and so on. Together, these features provide the necessary variation to enable recognition of each elephant within a population.

In both the 1976-79 and current Addo elephant studies, every elephant within the park was identified and a photographic record of the population compiled. Identification photographs of each adult and juvenile were taken from both the right and the left side, clearly showing ear shape and blood vessel patterns, pattern of wrinkles on the face, and tusks (where present). Other distinctive features were also photographed. Not all calves ( 6 years of age or less) were photographed systematically, because these youngsters could be identified most easily by means of association with their mother. Each elephant was sexed and its approximate age estimated, based on size and developmental state. Associations between individuals were recorded, and the composition of family groups identified.

\section{Reconstruction of population history}

Old photographs were used as a primary source of evidence in order to trace the elephants' life histories. Comparisons of photographs of known elephants taken between 1976 and 1998 revealed that patterns of facial wrinkles and blood vessels in the ears are unique for each elephant and, unlike characteristics such as tears in the ears or size, shape and configuration of the tusks, they do not change over time. Therefore, these features provide a reliable means of identifying individuals in photographs taken throughout their life. Dated photographs of newborn calves can be used to estimate dates of birth, and where calves are photographed with their mothers the pictures can also be used to ascertain maternal relationships.

Over 8600 dated photographs of the Addo elephants taken between 1934 and 1998 were compiled, together with three cine-films taken during the 1950s. Sources include: the two aforementioned studies; A.J.H.-M.'s regular visits to AENP (1980-96); South African National Parks (SANP) archives; local newspaper archives; published articles; local photographers; families of early park wardens; and responses to national public appeals (on TV; in various newspapers; Woodd, 1998). The individuals pictured in all photographs were, wherever possible, identified. Photographic evidence was studied in conjunction with all available documentation on the population: reports and letters from wardens and rangers to the National Park's Board (NPB)/SANP; newspaper clippings; published articles; and notes made by A.J.H.-M. during the 197679 study and during subsequent visits to the park.

Primarily, all individuals present in the population during the 1976-79 study were examined, and those still alive today identified. Those no longer living were traced through the records and the date of their disappearance from records was identified. This information, together with reports of deaths discovered, was used to ascertain their dates of death as accurately as possible.

All members of the current population that were not present during the $1976-79$ study must have been born since 1980. Working in reverse chronological order, individuals were traced back through their lives to the earliest available photographs of them, ideally as young calves. These photographs, together with any accompanying notes, were used to estimate dates of birth. Comparison of the estimated age of each individual in photographs taken in different years, as well as the current estimated age, provided a means of checking estimated dates of birth.

In the same way, individuals present in the 1976-79 study were traced back through the records in order to determine their dates of birth. In addition, all records were examined in order to determine the dates of birth and death of any individuals born during the park's history that were not present in the population during either the 1976-79 or the current studies.

Photographic and written records were also examined for evidence of sexual development of females 
(signs of development of the mammary glands, records of oestrous behaviour), and to estimate the dates of birth and ascertain the identity of calves born to sexually mature cows. Given the social behaviour of elephants, an isolated observation of a cow close to or even suckling a young calf does not necessarily mean that this calf belongs to the cow. Allomothering is common amongst subadult female elephants (Lee, 1987), and even fully mature adult cows are observed occasionally to care temporarily for calves who do not belong to them, sometimes even tolerating the calf sucking (A.J.H.-M. \& A.M.W. pers. obs.). Therefore, multiple sources of evidence (identified photographs of the cow-calf pair taken on different occasions and in different years, supporting notes, and so on) were always sought.

Current association patterns were observed and supporting evidence for proposed cow-calf bonds sought. The matriarchal family groups, consisting of related cows and their offspring, into which elephant society is organized, show long-term stability, and the bond between an elephant cow and her female offspring often remains strong throughout the life-span of the pair (Moss \& Poole, 1983; Moss, 1988). Thus, any female offspring born in Addo are likely to still associate closely with their mothers, and belong to the same family group. Close associations would also be expected between males of less than $c .12$ years of age and their mother's family group. Thereafter, as sexual maturity is reached, male calves are evicted from the family group to lead a bachelor life, forming no long-term stable associations (Moss \& Poole, 1983; Moss, 1988).

All proposed dates of birth and cow-calf pair bonds were checked to ensure that no data generated suggested inter-calf intervals of less than 22 months (the gestation period of elephants), and no individual had been 'double counted' and identified as the calf of more than one female.

\section{Demographic analysis}

Data on birth dates and cow-calf relationships were used to compile the maternal family trees for the population dating back to 1931. A register of every elephant living within the park at the end of each year was drawn up and annual total population sizes calculated.

In this paper, demographic analysis for the past 23 years is presented. Analysis of the longer term data set and consideration of changes to the population's demographic parameters during the park's history is under way.

Observed annual exponential rate of increase $(r)$ and the percentage population growth were calculated as follows (Caughley \& Sinclair, 1994): $r=\log _{e}\left(N_{t+1} / N_{t}\right) ;($ where $n=$ population size; $t=$ time $)$

$\%$ population growth $=\left(e^{r}-1\right) \cdot 100 \%$.

Female fecundity was examined and the following parameters calculated: inter-calving interval; age of sexual maturity; age of reproductive senescence; fertility and age-specific fecundity. The latter is based on the fecundity of females in the population at the end of 1995. Fecundity is expressed as the number of cows who are pregnant (calf born by October 1997) added to the number of cows who are lactating (calf born 199295), divided by the total number of cows in that age class. A cow could be both lactating and pregnant, so the calculated figure for fecundity can exceed 1 .

A life table for the population was constructed: the total number of elephants entering each age class (year $0,1,2$, etc.) during the years 1976-98 was summed and total number of deaths in each age class used to calculate age-specific mortality. Mean annual mortality was also calculated.

\section{Results and discussion}

Life histories of individual elephants were traced successfully throughout the park's history, and maternal family trees compiled. As an example, photographs of one cow taken over a period spanning 35 years are shown (Plate 1), and the corresponding family tree is given (Fig. 1).

Increase in annual population size throughout the park's history is illustrated (Fig. 2). The total number of elephants that have, at any stage, been present within AENP (1931-98) is 370. This figure is a minimum estimate because it is possible that elephants have been born and have died unrecorded during the history of the park.

\section{Population history, 1976-present}

A high proportion ( 75 per cent) of the photographic evidence consists of photographs taken between 1976 and 1998, providing detailed data on the elephants within the population during this period. Of the 284 elephants currently (31 December 1998) living within the park, 64 were present in the population of 94 elephants at the end of 1976. A total of 247 births and 53 deaths occurred between 1 January 1977 and 31 December 1998. Five calves were translocated from AENP to Pilanesberg National Park in October 1979, but one of these was returned within a fortnight. No other immigrations or emigrations have occurred since the creation of the AENP. 


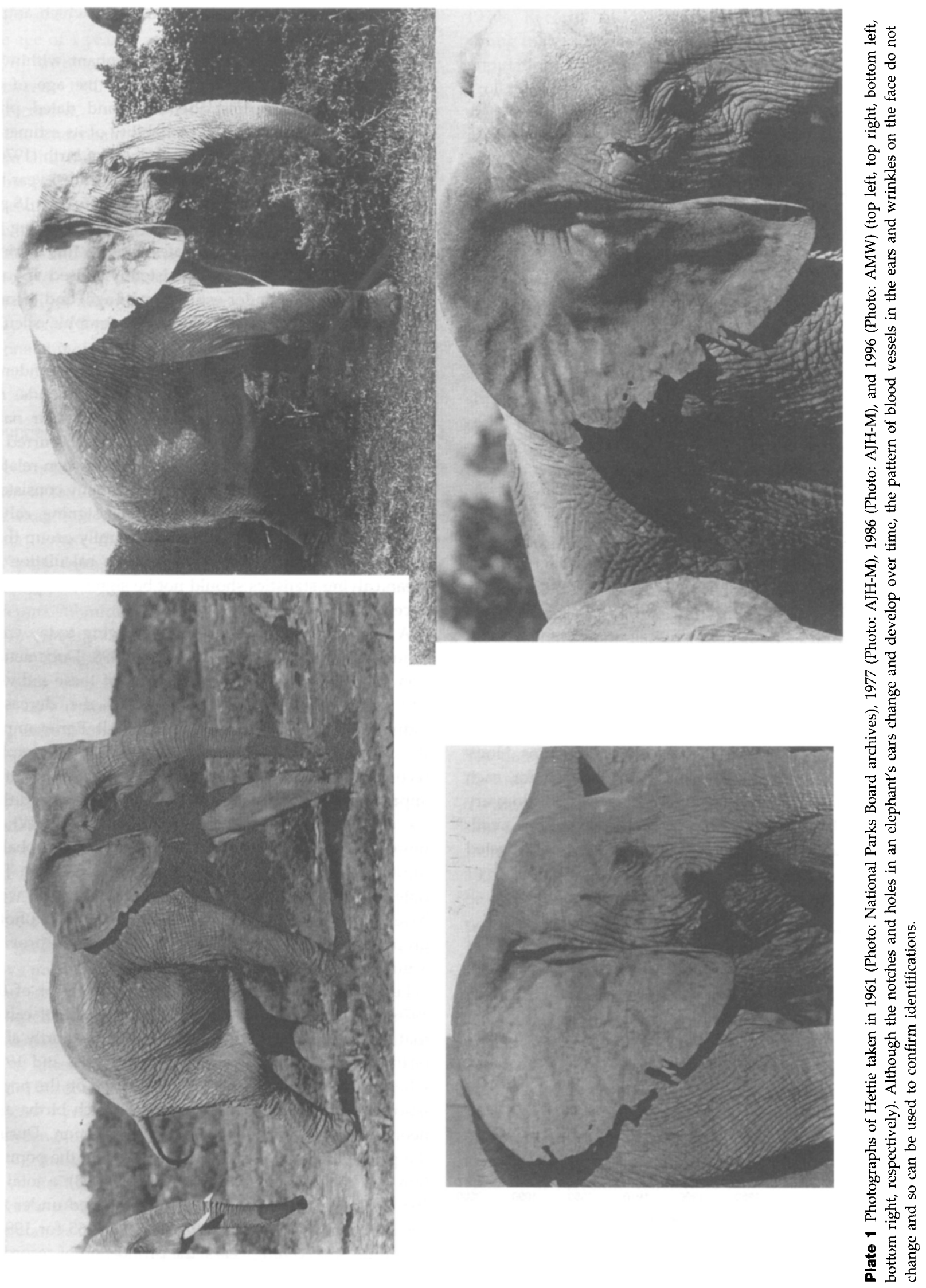




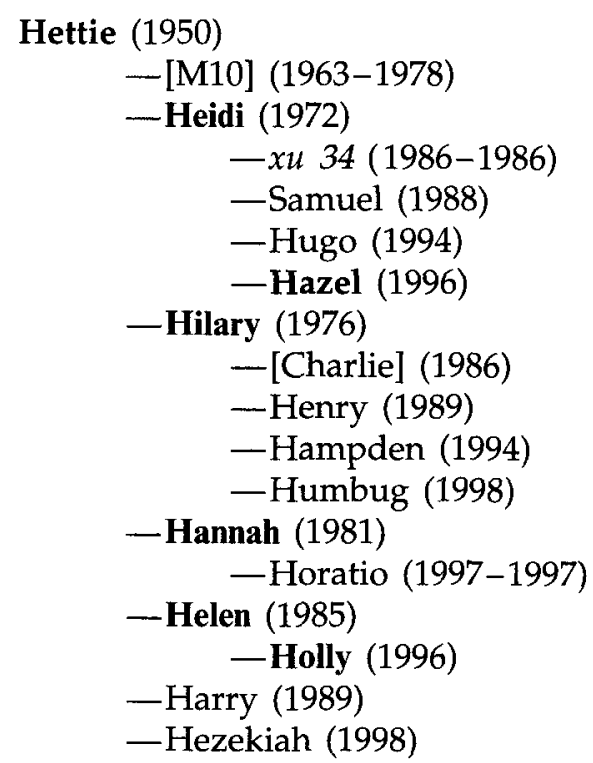

Fig. 1 Maternal family tree of the ' $\mathrm{H}^{\prime}$ family. Explanatory notes: calves are indented below their mother; sex is indicated as follows: bold type $=$ female, ordinary type $=$ male, italics = unsexed; year of birth is given in parentheses after each individual; for animals no longer living, year of death is indicated after year of birth; square brackets indicate sexually mature bulls that no longer associate with the family.

Overall, the data are considered to be relatively reliable because assumptions and inaccuracies were minimized by seeking repeated confirmation of all suggested dates of birth, death and relationships. However, the quantity and quality of evidence for each individual elephant throughout this period do vary and, for those animals for which less evidence is available, the accuracy of generated data cannot be expected

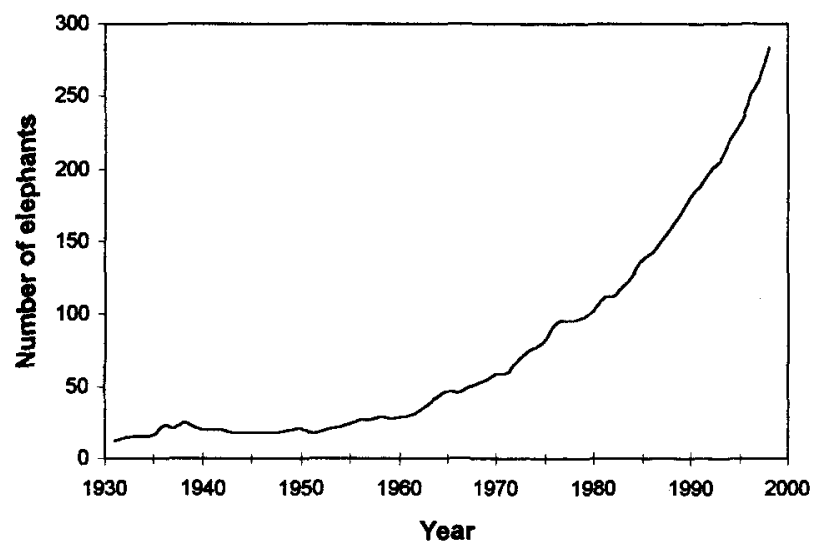

Fig. 2 Addo elephant population size, 1931-98, derived from reconstructed annual population estimates. to be as great as it is for individuals for which ample detailed information is available.

Identified photographs of every elephant within its first year of life are not available. As the age of an individual in the earliest identified and dated photograph of it increases, so the reliability of its estimated year of birth decreases. Estimated dates of birth (197698) are considered to be accurate to the nearest year for 70 per cent of births, to \pm 1 year for a further 18 per cent of births, and to \pm 2 years for the remaining 12 per cent of suggested birth dates during this period. Errors are unlikely to be consistently biased in one direction (over- or under-estimation of age) and, hence, inaccuracies should cancel out in demographic calculations.

Sufficient evidence is available to enable confidence in the majority of proposed cow-calf pair bonds. All calves born could be reliably assigned to their natal family group, so that any errors that have occurred in the proposed mothers of calves will be between related cows within the family. It is unlikely that any consistent bias will have occurred (repeatedly assigning calves to younger or older cows within the family group than to the actual mother) and, hence, the calculation of mean calving statistics should not be significantly influenced.

A total of 53 elephants no longer living today were found in records between 1976 and 1998. Documentation of 44 deaths was found, and all of these individuals were identified. In some cases the deceased individual had to be identified by default. For example, if an individual disappeared from the photographic record just prior to the reported death of an elephant of appropriate age and sex class, it would be assumed that the dead elephant was the missing individual. Where more than one animal is missing, the most probable individual was assigned to the given death event. The dates of death of the remaining individuals $(n=9)$ were based purely on their disappearance from the photographic records. In these cases, the death dates provide a minimum estimate of age of death.

Possibly the greatest potential source of error of the 1976-98 data lies in the number of records of calves that were born during this period but died shortly after birth without being recorded. Between 1980 and 1995, when no intensive research was conducted on the population, it is probable that a number of such births and neonatal deaths may have escaped detection. During the periods for which intensive research on the population has been conducted $(1976-79 ; 1996-98)$, a total of 10.5 per cent of all recorded calves born died under the age of 1 year $(n=2 / 21$ for $1976-79 ; n=7 / 65$ for $1996-$ 98). In the intervening years, the proportion of recorded calves born that died within their first year is just 
4 per cent $(n=7 / 175)$. If the death rate of calves under the age of 1 year is assumed to be constant throughout 1976-98, then a further 11 calves may have been born between 1980 and 1995, and subsequently died unrecorded.

The underestimation of the total number of calves born and the number of neonatal deaths will lead to some errors in calculated demographic parameters. As a result, the given inter-calf interval and age of first calving are maximum estimates (cows may have given birth to additional calves between recorded offspring or prior to their first recorded offspring); age-specific fecundities are minimum estimates (unrecorded calves may have been produced by cows of all ages); and neonatal mortality rate is a minimum estimate. Calculations of population growth rates will not be affected.

\section{Founder population, 1931}

Records left by Trollope, the park's first warden, in the form of letters and reports, are not entirely clear as to the exact size and composition of the elephant population when the animals were initially driven into the park from surrounding farmland in October 1931 (Trollope, 1931a,b). The most detailed information is a report submitted to the NPB by Trollope (1931a) on 1 November 1931, in which he wrote:

'With regard to the number of elephants I am sure of not less than 10, there may possibly be 11 , but not more ... They are a sociable troop, there is one big bull and another more than half grown, the balance are females and young things'.

During 1935/36 eight calves were born (photographic evidence, plus excerpts from NPB reports). It is unlikely that any were twins because twinning in elephants is rare (Laws, 1967; Hanks, 1972; Smuts, 1975), and if any such births had occurred it is highly improbable that the event would not be documented. Therefore, given the gestation period of elephants, eight sexually mature cows must have been present in the population at this time in order to produce these calves. The earliest reported age of female sexual maturity amongst elephants is 7 years (Laws \& Parker, 1968) and, therefore, all of these eight cows must have been amongst the initial October 1931 population, and all must have been at least 4 years old at the time. Four calves were born between November 1931 and September 1932 (Trollope, 1932), indicating that at least four of the eight initial cows must have been sexually mature by 1931 . Further records of births and photographic evidence of the population in 1936 suggest that six of the initial eight cows were sexually mature on entering the park and the remaining two were probably born in the mid 1920s. Records and photographs also indicate that a young male calf was amongst the initial Addo elephant population. Therefore, the initial total must have been Trollope's higher estimate of 11 animals, consisting of eight females (six sexually mature and two immature) and three males (two mature-one full-grown, one half-grown-and one calf). On 11 November 1931 the birth of a calf in the park was reported (Trollope, 1931c), giving an end of year population size of 12 .

\section{Population history, 1931-76}

Fewer photographic records are available for the years prior to 1976. Smaller population sizes, as well as a 9-year hiatus (1939-47) in recruitment as a result of a lack of sexually mature bulls, facilitated the early reconstruction of the population's history. Greater reliance could be placed on written reports to fill gaps between photographs because, with fewer elephants to keep track of, rangers were able to keep relatively detailed and reliable records of births, deaths and population size.

However, not all written records were found to be accurate. In several instances reports contradicted one another and in some cases documented information was wrong. For example, all written records stated that the elephant population comprised 2 adult bulls, 8 adult cows and 10 calves at the end of 1954, the year in which the park was fenced. However, photographic evidence and cine-film footage of the park reveals that there were, in fact, 3 adult bulls, 8 cows and 11 calves. The number of elephants present at the end of 1954 was 22 , and not 20 as other records stated.

After an initial slow growth rate, the population is now increasing rapidly (Fig. 2). Data on annual recruitment, mortality and total population size throughout 1931-76 are considered relatively reliable, and so can be used in analysis of the population's growth and recovery since the creation of the park.

The limited photographic evidence prior to 1976 precludes confident identification of the mother of every elephant born during these years. For all surviving female calves born since 1948 (when breeding resumed, after the 9-year period with no recruitment), as well as any males who were less than $c .12$ years old in 1976 $(n=59)$, mothers' identities are suggested on the basis of behavioural observations made from 1976 onwards. For male calves born since 1948 who have been identified in photographs repeatedly sucking from and/or close to a breeding cow, plus one unsexed calf who died shortly after birth but whose mother is clearly identified in the records, $(n=6)$, the relationship between mother and calf could be ascertained with reasonable certainty. For the remaining post-1948 calves 
Table 1 End of year population sizes, annual births, deaths, growth and mortality rates for the Addo elephant population, 1976-98

\begin{tabular}{|c|c|c|c|c|c|c|}
\hline Year & Population size at end of year & Births & Deaths & Exponential rate of increase $(r)$ & $\%$ population growth & $\%$ mortality \\
\hline 1976 & 94 & 11 & 0 & 0.12 & 13.3 & 0 \\
\hline 1977 & 96 & 4 & 2 & 0.02 & 2.1 & 2.1 \\
\hline 1978 & 96 & 2 & 2 & 0.00 & 0.0 & 2.1 \\
\hline 1979 & 98 & 9 & $3+4^{*}$ & 0.02 & 2.1 & 3.1 \\
\hline 1980 & 103 & 5 & 0 & 0.05 & 5.1 & 0 \\
\hline 1981 & 111 & 12 & 4 & 0.07 & 7.8 & 3.6 \\
\hline 1982 & 113 & 4 & 2 & 0.02 & 1.8 & 1.8 \\
\hline 1983 & 120 & 8 & 1 & 0.06 & 6.2 & 0.8 \\
\hline 1984 & 128 & 9 & 1 & 0.06 & 6.7 & 0.8 \\
\hline 1985 & 138 & 10 & 0 & 0.08 & 7.8 & 0 \\
\hline 1986 & 142 & 11 & 7 & 0.03 & 2.9 & 4.9 \\
\hline 1987 & 151 & 10 & 1 & 0.06 & 6.3 & 0.7 \\
\hline 1988 & 160 & 11 & 2 & 0.06 & 6.0 & 1.25 \\
\hline 1989 & 170 & 10 & 0 & 0.06 & 6.3 & 0 \\
\hline 1990 & 181 & 11 & 0 & 0.06 & 6.5 & 0 \\
\hline 1991 & 189 & 8 & 0 & 0.04 & 4.4 & 0 \\
\hline 1992 & 199 & 12 & 2 & 0.05 & 5.3 & 1.0 \\
\hline 1993 & 205 & 13 & 7 & 0.03 & 3.0 & 3.4 \\
\hline 1994 & 220 & 15 & 0 & 0.07 & 7.3 & 0 \\
\hline 1995 & 232 & 18 & 6 & 0.05 & 5.5 & 2.6 \\
\hline 1996 & 249 & 19 & 2 & 0.07 & 7.3 & 0.8 \\
\hline 1997 & 261 & 17 & 5 & 0.05 & 4.8 & 1.9 \\
\hline 1998 & 284 & 29 & 6 & 0.08 & 8.8 & 2.1 \\
\hline
\end{tabular}

* Indicates calves translocated out of AENP to Pilanesberg National Park, October 1979.

( $n=18)$ mothers are suggested on the basis of which sexually mature cows were available for calving in the estimated year of birth. Finally, for calves born between 1931 and $1938(n=18)$ suggested mothers are more speculative. For example, it is suggested that the larger of the two original tusked cows is the mother of CAT and BUT. CAT was one of the first calves to be born after the proclamation of the park (from her age in 1936 photographs), and so her mother must have been one of the five original sexually mature cows. Although CAT only had one (right) tusk, two of her female offspring (BCA and $\mathrm{BCH}$ ) have two tusks. Behavioural observations suggest that BUT was probably CAT's younger sister. Clearly, many of these proposed cowcalf bonds are based on insufficient evidence to form the basis of any robust analyses.

\section{Demographic analysis}

Mean annual population growth rate for the period $1976-98$ is 5.53 per cent ( $\mathrm{SD}=2.82$; Table 1$)$. Calef (1988) predicted a maximum rate of increase for elephant populations of 7 per cent. Despite the closed nature of the Addo elephant population and the current high density (2.8 elephants per sq $\mathrm{km}$ ), the observed population growth rate is relatively rapid, indicative of a healthy, growing population.
The mean inter-calf interval is 3.8 years $(\mathrm{SD}=1.29$, $n=164$; Fig. 3). This is a maximum estimate, because it is possible that calves have been born and died unrecorded. This figure compares favourably with other populations: $3.5-4$ years in the Luangwa Valley, Zambia (Hanks, 1972); 4.7 years in the Kruger National Park, South Africa (Smuts, 1975); and 4.7 years in the Manyara National Park, Tanzania (Douglas-Hamilton, 1972).

The earliest age at which Addo cows have produced their first calf is 10 years; by 16 years of age, 95 per cent

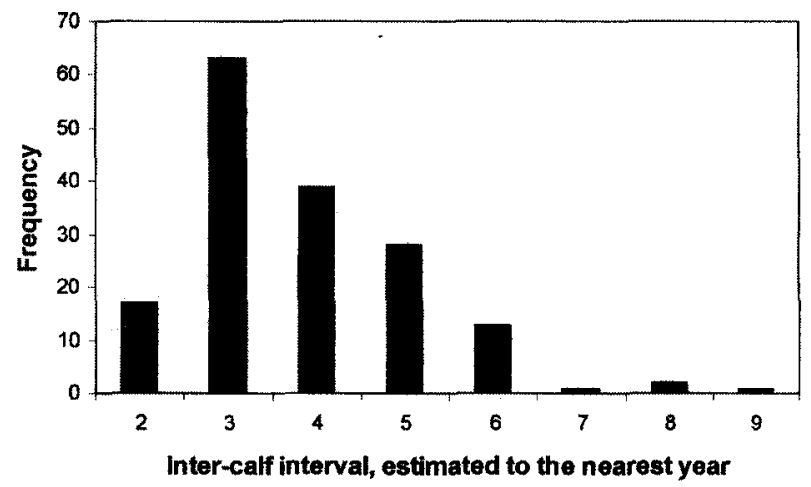

Fig. 3 Frequency distribution of inter-calf intervals for the Addo elephant population. 


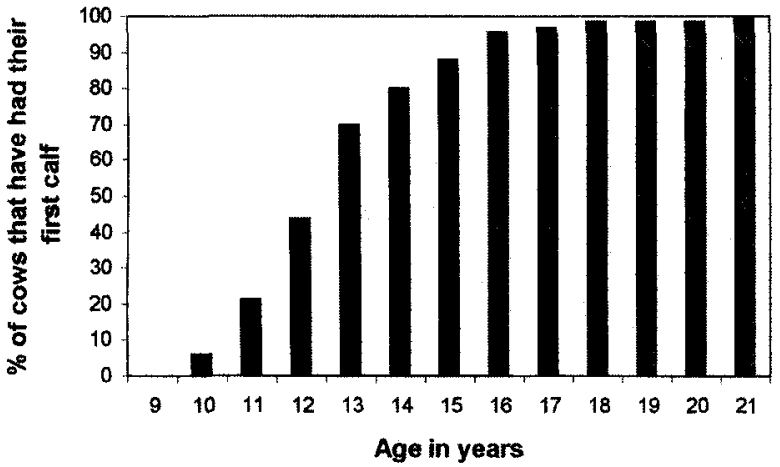

Fig. 4 Age frequency distribution of cows that have had their first calf for the Addo elephant population.

of cows have had at least one calf (Fig. 4). Mean age of first calving is 13.0 years $(\mathrm{SD}=2.03, n=66)$. Given the gestation period of the African elephant ( 22 months) this gives a mean age of first conception of 11.2 years. This figure lies within the usual range (7-15 years) of female sexual maturity (Laws \& Parker, 1968; DouglasHamilton, 1972; Hanks, 1972; Smuts, 1975). As a result of the possibility of unrecorded births, miscarriages and resorption of foetuses, this figure provides a maximum estimate of the age of first conception.

Insufficient data are available for reliable calculation of the age of female reproductive senescence. Only five cows within AENP are known to have lived to beyond 50 years of age. These cows gave birth to their last calves at the estimated ages of 48, 50, 50, 54 and 55 years, respectively. In addition, two younger cows appear to have ceased breeding (time since last calf $>$ longest recorded inter-calf interval). One of these (currently 45 years) gave birth to her last calf 17 years ago, having had a total of five calves, and now has the shrivelled and drooping breasts typical of an older cow who has long ceased lactation. The other (currently 35 years) has the flat chest of a sexually immature cow, although she is known to have had one calf when she was 18 years old (17 years ago). This latter cow appears to be relatively infertile and is, therefore, not included in calculations of the age of reproductive senescence. Calculation of the average age of female reproductive senescence based on the other six cows gives a tentative estimate of 49.2 years ( $\mathrm{SD}=8.73, n=5$ ). Most studies have shown a decline in reproductive activity beyond the age of 50 years, although reproductive activity in the 56-60 year age classes has been reported (Smuts, 1975). Smut's estimations of cows' ages were based on the assessment of the lower jaw using criteria described by Laws (1966). However, there have been some discussions of errors associated with this technique (Jachmann, 1985, 1988) and the accuracy of ageing

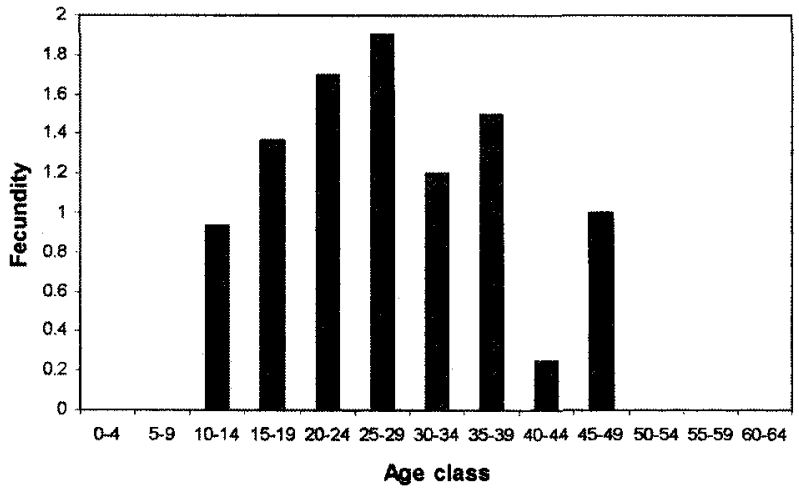

Fig. 5 Age-specific fecundity of cows within the Addo Elephant National Park.

older elephants using Laws' criteria has not been quantified. It is possible that the relatively high age of reproductive activity reported by Smuts is an artefact of errors in ageing the cows.

Fertility amongst adult females is high: of the total number of sexually mature cows under the age of 49 ( $n=75), 95$ per cent are currently breeding (pregnant and/or lactating). Of the four cows not currently breeding, two had their last calves 7 and 8 years ago, respectively (to date, longest recorded inter-calf interval in Addo $=9$ years; Fig. 4); and two had their last calf 17 years ago. Of these latter two, one ceased breeding at the age of 38 years, having had a total of five calves, and the other has only ever had one calf, at the age of 18 years. The age-specific fecundity of cows at the end of 1995 is illustrated in Fig. 5. A peak in fecundity is demonstrated for cows within the 25-29 year age class. This can be compared with a peak amongst 18-19 year olds observed by Hanks (1972) and a peak in the 31-35 year age group observed by Laws et al. (1970).

Mean annual mortality for $1976-98$ is 1.43 per cent $(\mathrm{SD}=1.39$; Table 1). Mortality for calves in their first year is 6.2 per cent (Table 2). Mortality rates then decrease, and the mean mortality for all elephants between the ages of 1 and 49 years is 1.8 per cent. Overall, mortality in the Addo elephant population is relatively

Table 2 Age-specific mortality rates for the Addo elephant population, 1976-98

\begin{tabular}{ll}
\hline Age class & Mortality rate $(\%)$ \\
\hline 0 & 6.2 \\
$1-9$ & 0.5 \\
$10-19$ & 1.0 \\
$20-29$ & 1.4 \\
$30-39$ & 2.7 \\
$40-49$ & 3.1 \\
$50+$ & 13.5 \\
\hline
\end{tabular}


low in comparison with figures quoted in the literature (10 per cent juvenile mortality and 3-5 per cent adult mortality; Laws \& Parker, 1968; Douglas-Hamilton, 1972).

\section{Conclusion}

The reconstruction of the Addo elephant population's history has created a unique data set, spanning 67 years and enabling long-term demographic analysis of the population. Despite a few inevitable questions that remain (not all birth dates are known to the nearest year and it is not possible to identify the mother of every calf born), abundant valuable data, not all of which are presented or analysed here, have been generated.

These detailed long-term data will enable in-depth investigation of population structure and social organization over time, examination of the population's growth and recovery from its former bottleneck, and evaluation of the effects of past management practices on the population. Issues concerning the current and future management of the population will be addressed in the light of all findings. A proposed significant enlargement of the AENP (Kerley \& Boschoff, 1997) would enable a tenfold increase in the size of the elephant population. Modelling to predict population growth as the park expands has been based on demographic parameters calculated from the population's long-term data set (Woodd, 1999).

Similar reconstructions of population history would be possible, given sufficient historical records, in other elephant reserves containing relatively small populations within closed systems. Efforts made to initiate studies elsewhere are recommended. As this study highlights, such endeavours could prove potentially fruitful.

\section{Acknowledgements}

Sincere thanks to the SANP for permission to work in AENP and for access to historical photographs and written reports. Thanks also go to all those (too numerous to name) who have provided historical material on the Addo elephant population. Logistical and financial support for this research was provided by the following: SANP, International Fund for Animal Welfare, University of Port Elizabeth and Foundation for Research Development. The authors also thank Graham Kerley for comments and criticism of this paper.

\section{References}

Calef, G.W. (1988) Maximum rate of increase in the African elephant. African Journal of Ecology, 26, 323-327.
Caughley, G. \& Sinclair, A.R.E. (1994) Wildlife Ecology and Management. Blackwell, Cambridge, MA.

Douglas-Hamilton, I. (1972) On the ecology and behaviour of the African elephant. The elephants of Lake Manyara. DPhil Thesis, University of Oxford.

Goodall, J. (1986) The Chimpanzees of Gombe: Patterns of Behavior. Harvard University Press, Cambridge.

Hall-Martin, A.J. (1992) Distribution and status of the African elephant Loxodonta africana in South Africa, 1652-1992. Koedoe, 35, 65-88.

Hanks, J. (1972) Reproduction of elephant, Loxodonta africana, in the Luangwa Valley, Zambia. Journal of Reproduction and Fertility, 30, 13-26.

Hoffman, M.T. (1993) Major P.J. Pretorius and the decimation of the Addo elephant herd in 1919-1920: important reassessments. Koedoe, 36, 23-44.

Jachmann, H. (1985) Estimating age in African elephants. African Journal of Ecology, 23, 199-202.

Jachmann, H. (1988) Estimating age in African elephants: a revision of Laws' molar evaluation technique. African Journal of Ecology, 26, 51-56.

Kerley, G.I.H. \& Boschoff, A. (1997) A Proposal for a Greater Addo National Park. A Regional and National Conservation and Development Opportunity. Terrestrial Ecology Research Unit, Report No. 17, unpublished report, University of Port Elizabeth, South Africa.

Laws, R.M. (1966) Age criteria for the African elephant. East African Wildlife Journal, 4, 1-37.

Laws, R.M. (1967) Occurrence of placental scars in the uterus of the African elephant Loxodonta africana. Journal of Reproduction and Fertility, 14, 445.

Laws, R.M. \& Parker, I.S.C. (1968) Recent studies on elephant populations in East Africa. Symposium of the Zoological Society of London, 21, 319-359.

Laws, R.M., Parker, I.S.C. \& Johnstone, R.C.B. (1970) Elephants and habitats in Northern Bunyoro, Uganda. East African Wildlife Journal, 8, 163-180.

Lee, P.C. (1987) Allomothering among African elephants. Animal Behaviour, 35, 278-291.

Martin, R.B. (1978) Aspects of elephant social organisation. Rhodesian Science News, 12, 184-187.

Moss, C.J. (1981) Social circles. Wildlife News, 16, 2-7.

Moss, C.J. (1988) Elephant Memories. Fontana, Glasgow.

Moss, C.J. (1996) Getting to know a population. In Studying Elephants, AWF Technical Handbook Series 7 (ed. K. Kangwana), pp. 58-74. African Wildlife Foundation, Nairobi.

Moss, C.J. \& Poole, J. (1983) Relationships and social structure of African elephants. In Primate Social Relations (ed. R. A. Hinde), pp. 315-325. Blackwell Scientific Publications, Oxford.

Smuts, B.B., Cheney, C.L., Seyfarth, R.M., Wrangham, R.W. \& Struhsaker, T.T. (1987) Primate Societies. University of Chicago Press, Chicago.

Smuts, G.L. (1975) Reproduction and population characteristics of elephants in the Kruger National Park. Journal of the Southern African Wildlife Management Association, 5, 1-10.

Trollope, S. (1931a) Ranger's report on the Addo Elephant National Park, 1 November 1931. Unpublished internal report, National Parks Board, Pretoria. 
Trollope, S. (1931b) Various letters to National Parks Board concerning drive of elephants into AENP: 9, 12, 16, 19 October 1931. Unpublished internal archives, National Parks Board, Pretoria.

Trollope, S. (1931c) Letter to National Parks Board, November 1931. Unpublished internal archives, National Parks Board, Pretoria.

Trollope, S. (1932) Ranger's report on the Addo Elephant National Park, 9 September 1932. Unpublished internal report, National Parks Board, Pretoria.

Wells, R.S. (1991) The role of long-term study in understanding the social structure of a bottlenose dolphin society. In Dolphin Societies: Discoveries and Puzzles (eds K. Pryor and K. S. Norris), pp. 199-225. University of California Press, Berkeley.

Woodd, A.M. (1998) Addo's elephants: will they survive the twenty-first century? Custos, May, 19-21.

Woodd, A.M. (1999) A demographic model to predict future growth of the Addo elephant population. Koedoe, 42, 97-100.

\section{Biographical sketches}

Anna Whitehouse (née Woodd) graduated in zoology at Cambridge University in 1994. Her passion for elephants took her out to South Africa in 1996, to work in the Addo Elephant National Park. Focusing on the Addo elephants, her research includes aspects on the population's history, demography, behaviour and genetics. She is currently writing up her PhD thesis, and hopes to continue her research, and related education and conservation work, for the foreseeable future.

Dr Anthony Hall-Martin started working on the Addo elephants in 1976, and compiled the first population register for them when they numbered only 77 animals. He has worked extensively on the ecology, behaviour and management of the African elephant ever since. The focus of his studies for many years was the Kruger National Park population, which is intensively managed. In addition to an interest in elephants he has also been active in the black rhinoceros conservation programme of the South African National Parks where he is currently Director: Conservation Development. 